\title{
Detection of Sinkhole Precursors Through SAR Interferometry: Radar and Geological Considerations
}

\author{
Andre Theron, Graduate Student Member, IEEE, Jeanine Engelbrecht, Jaco Kemp, Waldo \\ Kleynhans and Terrence Turnbull
}

\begin{abstract}
Sinkholes are an unpredictable geohazard that endangers life and property in dolomitic terrains. Sinkholes are a significant threat in Gauteng, South Africa's most populated and urbanised province. Small-scale surface subsidence is frequently present prior to the collapse of a sinkhole. Therefore, the presence of precursory surface deformation can be exploited to develop early warning systems. Spaceborne SAR interferometry (DInSAR) is able to monitor small-scale surface deformation over large areas and can be used to detect and measure precursors to sinkhole development. This paper investigates the use of repeat-pass DInSAR to detect sinkhole precursors in the Gauteng Province. Twenty stripmap acquisitions from TerraSAR-X were acquired over a full year. DInSAR results revealed the presence of three previously unknown deformation features, one of which could be confirmed by subsequent field investigations. Furthermore, a water supply pipeline ruptured 6 months after the initial observation. The detection of the deformation, therefore, provided a viable early warning to landowners who were unaware of the subsidence. Detected deformation features were between $40 \mathrm{~m}$ and $100 \mathrm{~m}$ in diameter. The maximum displacement measured was $50 \mathrm{~mm}$ over 55 days. Despite the successful detection, seven sinkhole events occurred in the observation period for which no deformation could be detected. The results indicate that high-resolution, $\mathrm{X}$-band interferometry is able to monitor dolomite-induced instability in an urban environment. However, considerations related to SAR interferometry and physical sinkhole properties need to be addressed before DInSAR can be used in an operational early warning system.
\end{abstract}

Index Terms-Geophysical measurements, hazardous areas, interferometry, land surface, spaceborne radar, synthetic aperture radar (SAR).

This work was financially supported by the Council for Scientific and Industrial Research's studentship program.

A.Theron (corresponding author e-mail: atheron1@csir.co.za) and J. Engelbrecht are with the Satellite SAR research Group, Meraka Institute, Council for Scientific and Industrial Research, Stellenbosch 7600, South Africa, and the Department of Geography and Environmental Studies, Stellenbosch University, Stellenbosch 7600, South Africa.

J. Kemp is with the Department of Geography and Environmental Studies, Stellenbosch University, Stellenbosch 7600, South Africa.

W. Kleynhans is with the Department of Electrical, Electronic and Computer Engineering, University of Pretoria, Pretoria 0028, South Africa, and the Satellite SAR research Group, Meraka Institute, Council for Scientific and Industrial Research, Pretoria 0001, South Africa.

Terrence Turnbull is with the South African Air force.

\section{INTRODUCTION}

INKHOLE formation occurs where the bedrock comprises $\checkmark$ of highly soluble evaporites or calcium carbonates such as dolomite or limestone. Subsurface cavities are formed mainly due to groundwater extraction or the ingress of water, often from leaking services or poor storm water drainage. Both ultimately lead to the erosion of weathered roof material into cavities and the subsequent collapse of the roof strata. Sinkholes are a growing concern globally due to increasing urbanisation and development on susceptible areas [1]. Although sinkholes appear with little warning, the appearance of tension cracks, cracks in infrastructure and surface subsidence are often early warning signs of sinkhole development. Such surface deformation occurs weeks to months before sinkhole formation as the erosion of the roof material causes upward migration of the cavity [2]. Sinkhole formation is by nature abrupt and the location of underground cavities is frequently unknown. It is therefore challenging to identify and analyse the associated small-scale precursory deformation. Furthermore, in situ monitoring of large areas is not feasible.

Satellite-based Synthetic Aperture Radar (SAR) systems are a valuable and proven tool in deformation detection and monitoring due to their frequent repetition time, large swath coverage and high precision. Sinkholes are more challenging to detect than larger scale deformation features due to their small size, unpredictable nature and non-linear deformation rate. Recent research has indicated that precursory surface subsidence can occur and that differential interferometry techniques (DInSAR) can accurately detect it months to years before the event (see [2]-[5]). It has, however, been found that some collapse sinkholes did not exhibit precursory subsidence and not all deformation events lead to collapse events [6].

Despite a need for more research, there is optimism that reliable sinkhole precursor detection using DInSAR techniques, especially in urban areas, are cost effective and feasible [7]-[11]. However, available research is based on specific radar systems and only a limited number of sinkhole events under local geologic conditions. Since sinkholes are low-probability/high-impact events, there is a strong incentive to apply this technology to collect more evidence regarding 
precursory ground motion. It is important that investigations be done over various subsidence hazard-prone regions of the world but in particular over the susceptible urban areas of South Africa.

An estimated 25\% of the Gauteng Province of South Africa is underlain by dolomite. There have been over 3000 sinkhole related events over the last 60 years, resulting in the loss of lives and damage to property exceeding 1 Billion Rands (approx. 70 million USD) [12]. This paper explores the ability of DInSAR to detect precursory subsidence in a sinkhole prone urban area in the Gauteng Province. The data and processing framework are provided in Section II. The results are presented in Section III and are centred on a case study. A discussion of challenges to reliable detection identified during the study is presented in Section IV.

\section{DATA AND METHODS}

This study used the TerraSAR-X and TanDEM-X satellites collecting repeat-pass data in Stripmap mode in $\mathrm{HH}$ polarisation at an approximate incidence angle of $40^{\circ}$. The system's high spatial resolution $(2.7 \mathrm{~m})$, frequent revisit time (11 days) and sensitivity to deformation made it a promising platform for this investigation. Historically, sinkholes in the study area have been between $2 \mathrm{~m}$ and $15 \mathrm{~m}$ in size and high spatial resolution radar data was, therefore, an important consideration [12]. Data were acquired from 29 January 2015 to 27 January 2016 with revisit times of between 11 and 77 days, resulting in 21 interferometric pairs (Table I). Perpendicular baselines were generally low with a maximum of $365 \mathrm{~m}$ between 2015/02/09 and 2015/04/27.

Conventional repeat-pass differential interferometry was used to derive surface deformation maps of the area under investigation. The topographic phase was modelled using the 'SUDEM' (5m resolution, $10.2 \mathrm{~m}$ vertical RMSE and EGM96 geoid subtracted). This is an integration of the SRTM-1 and

TABLE I

\section{TERRASAR-X DATASET PROPERTIES}

\begin{tabular}{ccc}
$\begin{array}{c}\text { Acquisition } \\
\text { date }\end{array}$ & $\begin{array}{c}\text { Temporal baseline } \\
\text { (days) }\end{array}$ & $\begin{array}{c}\text { 1 } \\
\text { Perpendicular baseline } \\
\text { (metres) }^{\mathbf{1}}\end{array}$ \\
\hline $2015 / 01 / 29$ & 11 & 217 \\
$2015 / 02 / 09$ & 77 & 365 \\
$2015 / 04 / 27$ & 11 & 341 \\
$2015 / 05 / 08$ & 33 & 23 \\
$2015 / 06 / 10$ & 11 & 41 \\
$2015 / 06 / 21$ & 11 & 10 \\
$2015 / 07 / 02$ & 11 & 69 \\
$2015 / 07 / 13$ & 33 & 14 \\
$2015 / 08 / 15$ & 22 & 3 \\
$2015 / 09 / 06$ & 11 & 73 \\
$2015 / 09 / 17$ & 11 & 4 \\
$2015 / 09 / 28$ & 11 & 192 \\
$2015 / 10 / 09$ & 11 & 12 \\
$2015 / 10 / 20$ & 11 & 295 \\
$2015 / 10 / 31$ & 11 & 271 \\
$2015 / 11 / 11$ & 11 & 176 \\
$2015 / 11 / 22$ & 11 & 184 \\
$2015 / 12 / 03$ & 11 & 71 \\
$2015 / 12 / 14$ & 22 & 57 \\
$2016 / 01 / 05$ & 22 & 118 \\
$2016 / 01 / 27$ & N/A & N/A \\
\hline
\end{tabular}

${ }^{1}$ Relative to the following acquisition. the South African national height data set and allows for improved topographic modelling [13]. Single look complex images were co-registered to accuracies less than 0.1 pixels before interferogram generation. Although multilooking could be performed to reduce interferogram noise, the trade-off would be a reduction in resolution which could mask smallscale fringe patterns associated with sinkhole precursors. Furthermore, the process of filtering would impose additional losses in resolution. For this reason, full resolution interferograms with no multi-looking were generated and, to minimize noise, the interferograms were filtered using an adaptive Goldstein filter [14]. Filtering was performed with an alpha coefficient of 0.5 within a 32 × 32 Fast Fourier Transform (FFT) window. Coherence was estimated with a $5 \times 5$ pixel estimation window before filtering. Phase unwrapping was performed using the minimum cost flow algorithm with coherence as a weighting function [15]. Displacement maps were calculated in the line of sight (LOS) direction.

Ancillary data used for analysis of the results include rainfall accumulation at a station central to the study area. Rainfall was identified as a potential challenge to detecting deformation due to rainfall induced signal decorrelation. To determine the influence of rainfall on coherence, the rainfall accumulation between the dates of master and slave acquisition was calculated. In addition, an independent sinkhole inventory based on field observations was provided by the Council for Geoscience. Relevant entries are provided in Table II. This inventory is updated continuously by local authorities and was used to guide DInSAR analysis as well as assist in accuracy assessment and verification deformation detected if possible.

TABLE II

DETAILS OF SINKHOLE INVENTORY EVENTS

\begin{tabular}{|c|c|c|c|c|c|}
\hline Date & Type & Possible cause & $\begin{array}{l}\mathrm{D}_{\mathrm{x}}^{*} \\
(\mathrm{~m}) \\
\end{array}$ & $\begin{array}{l}\mathrm{D}_{\mathrm{y}}^{*} \\
(\mathrm{~m})\end{array}$ & $\begin{array}{l}\mathrm{D}_{z}^{*} \\
(\mathrm{~m})\end{array}$ \\
\hline $\begin{array}{l}\text { Mar } \\
2015\end{array}$ & Sinkhole & Leaking pipe & N/A & N/A & $\mathrm{N} / \mathrm{A}$ \\
\hline 2015 & Subsidence & Leaking pipe & 16 & 4 & 0.2 \\
\hline 2015 & N/A & Leaking pipe & N/A & N/A & $\mathrm{N} / \mathrm{A}$ \\
\hline 2015 & Subsidence & Leaking pipe & N/A & $\mathrm{N} / \mathrm{A}$ & $\mathrm{N} / \mathrm{A}$ \\
\hline $\begin{array}{l}3 \text { Jan } \\
2016\end{array}$ & Sinkhole & Leaking pipe & 20 & 13 & 9 \\
\hline Jan 2016 & Sinkhole & Leaking pipe & 6 & 3 & 2 \\
\hline $\begin{array}{c}29 \mathrm{Jan} \\
2016\end{array}$ & $\begin{array}{l}\text { Sinkhole \& } \\
\text { Subsidence }\end{array}$ & $\begin{array}{c}\text { Leaking sewer } \\
\text { pipe }\end{array}$ & $\mathrm{N} / \mathrm{A}$ & $\mathrm{N} / \mathrm{A}$ & $\mathrm{N} / \mathrm{A}$ \\
\hline
\end{tabular}

\section{RESULTS}

During the DInSAR observation period, seven sinkhole events, as outlined in Table II, were recorded in the field by the Council for Geoscience. It should be noted that, in some cases, the size of the sinkhole or subsidence feature could not be recorded due to a lack of access to the site where the incident occurred. There are also significant uncertainties associated with the exact date of the incident as shown in Table II. For each of the sinkhole events recorded in the 
inventory, the DInSAR results were examined to determine if precursory deformation could be observed.

It was found that no deformation associated with any of the events recorded in the inventory could be detected through conventional DInSAR on the TerraSAR-X data. In-depth investigations of each non-detection, including DInSAR results and field photographs, has been reported on [16]. Further analysis of DInSAR results revealed the presence of three deformation features that were not recorded in the inventory. All three features were detected between $2015 / 06 / 10$ and 2015/08/15. One feature was verified during subsequent field investigations after it led to water infrastructure damage [17]. The other two deformation features were characterised by deformation of less than $5 \mathrm{~cm}$ and were less than $100 \mathrm{~m}$ in diameter. These, however, could not be verified by in-field observations and are not considered further in this paper.

\section{A. Confirmed Deformation Event}

The differential interferograms and vertical displacement maps of the confirmed deformation event are presented in Fig. 1 and Fig. 2, respectively. The first subsidence observation between 2015/06/21 and 2015/07/02 revealed a feature of $60 \mathrm{~m}$ in diameter with a maximum deformation of $21.4 \mathrm{~mm}$ measured.

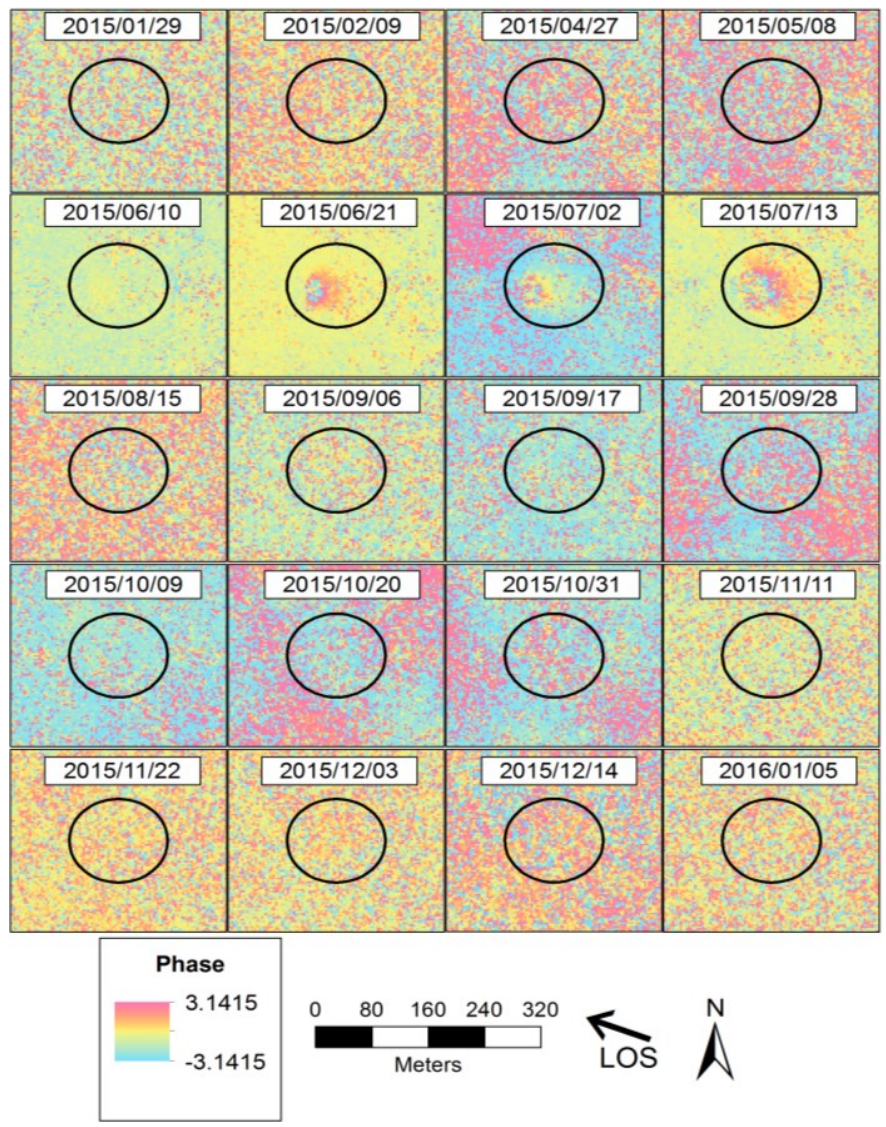

Fig. 1. Interferograms for the area surrounding the detected subsidence found within the black circle. Only the master date for each image pair is provided, the slave date of each image corresponds to the master date of the following image. The final slave date for the interferogram with the 2016/01/05 master is $2016 / 01 / 27$. Deformation fringes are visible between $2015 / 06 / 21$ and 2015/08/15.
The feature remained similar in extent over the next detection between 2015/07/02 and 2015/07/13 with a maximum of $30 \mathrm{~mm}$ of deformation observed. The final detection period between 2015/07/13 and 2015/08/15 was associated with an increase in the extent of the feature to $70 \mathrm{~m}$ in diameter with a maximum of $17.6 \mathrm{~mm}$ of subsidence observed. No further deformation associated with this feature was detected on subsequent image pairs.

The temporal baseline of the final pair (2015/07/13 to 2015/08/15) is longer (33 days) compared to the two initial pairs with temporal baselines of 11 days, possibly explaining the perceived increase in extent of the deformation feature. The observed deformation feature reached a total extent of 80 $\mathrm{m}$ in diameter over a period of 55 days with a maximum total LOS subsidence of $50 \mathrm{~mm}$ (Fig. 2).

It is unlikely that the observed features were the result of residual topography due to the very low relief over the feature (less than $1 \mathrm{~m}$ change in elevation) and the large ambiguity heights for the interferogram pairs $(453 \mathrm{~m}, 98 \mathrm{~m}$ and $393 \mathrm{~m}$ respectively). Residual atmospheric phase could also be ruled out due to the feature's small scale and high spatial correlation within the time series [18].

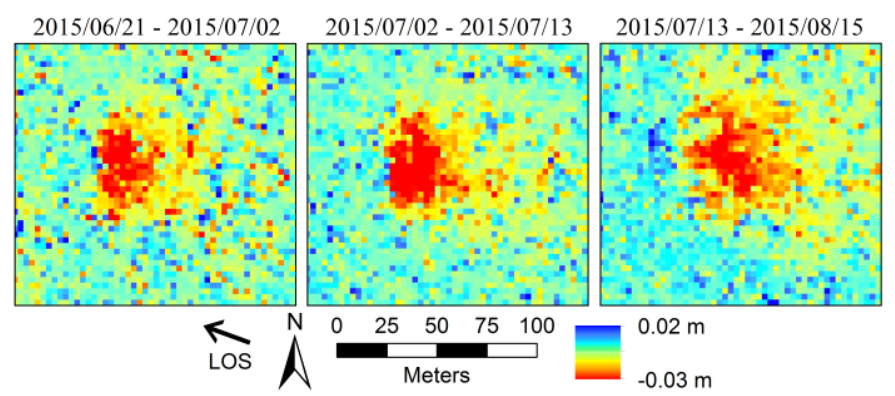

Fig. 2. Line of sight displacement maps of the deformation event derived from the three interferograms where deformation was detected.

Field investigation of the feature revealed the presence of tension cracks tens of meters long on the western periphery (Fig. 3). This is possible evidence of a steeper deformation gradient in the western edge of the feature.

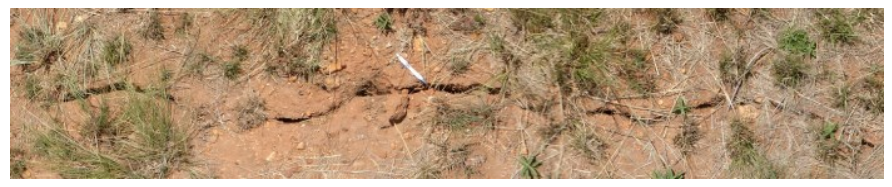

Fig. 3. A portion of an approximately $30 \mathrm{~m}$ long tension crack that was observed on the western edge of the deformation feature.

On 17 December 2015, a sinkhole of $0.5 \mathrm{~m}$ by $1.0 \mathrm{~m}$ was reported in the area, resulting in the rupturing of a water supply pipeline. The surface subsidence observed up to six months before using DInSAR were likely the result of subsurface erosion of the roof strata into a dolomite cavity leading to localized surface instabilities. Since the surface deformation was observed during a period associated with very little rainfall, it is postulated that the water supply pipeline was leaking and caused the erosion leading to the deformation. Landowners confirmed that the pipe was known 
to have leaked for at least a year prior to its rupture. The eventual rupturing of the water supply pipeline was likely due to the increased stress in the pipeline due to the deformation.

\section{DISCUSSION AND CONCLUSION}

This paper presents promising results from a dolomite stability-monitoring project. The high spatiotemporal resolution and small perpendicular baselines of the TerraSAR-X data, as well as the urban nature of the study area, enabled accurate detection of surface instabilities. Using conventional DInSAR techniques and a time-series of data revealed the presence of three deformation features. Subsequent field investigations revealed tension cracks associated with one feature thereby providing qualitative evidence of the $50 \mathrm{~mm}$ of deformation detected over 55 days. The observed surface subsidence up to six months prior to the formation of a small sinkhole that resulted in a burst pipeline is an encouraging indication that precursory deformation can be detected with DInSAR. However, the inability to detect any of the sinkhole events in the inventory reveals limitations to the technique and was investigated in more detail. It was found that the successful detection of sinkhole precursors through DInSAR is dependent on specific considerations that relate to 1) the properties of the SAR system and processing techniques applied to the data as well as 2) the geological signature of precursory deformation.

\section{A. SAR and Processing Considerations}

The resolution of the SAR system was identified as an important parameter for successful sinkhole precursor detection. It is known that deformation cannot reliably be detected by a single pixel [18] and the resolution of the SAR system, therefore, needs to be higher than the spatial scale of the deformation event. The largest sinkhole recorded in the inventory had a diameter of $20 \mathrm{~m}$. This corresponds to approximately seven pixels on the TerraSAR-X system. Identifying deformation on the interferograms and displacement maps produced by conventional DInSAR processing on less than 10 pixels is challenging [18]. The smallest confirmed detection during this study was in fact $60 \mathrm{~m}$. Smaller deformation-like fringe patterns were observed during the study but could not be distinguished from typical interferogram noise, a particular challenge for the X-band system. Advanced interferogram stacking techniques using coherent point and distributed targets [19] can detect deformation on a single pixel. However, these reduce the spatial sampling density of the study area considerably and deformation would not be detectable in areas without a coherent target. Therefore, in the absence of coherent pointtargets, the size of sinkhole events in relation to the resolution of the sensor would remain a limiting parameter.

Revisit time of the SAR is a further important consideration. A shorter revisit time (low temporal baseline) minimizes the chance that deformation will exceed the deformation gradient. It furthermore results in a higher temporal sampling of the deformation feature, as well as providing a more timely early warning of imminent sinkhole events. Short temporal baselines are also important for reducing phase decorrelation between image acquisitions, particularly in vegetated areas [20].

Temporal decorrelation was found to be an important limitation to DInSAR sinkhole precursor detection. During this study, it was noted that deformation was only detected during periods of high average scene coherence. In fact, based on the limited detections during this study, an average-scene coherence threshold of 0.4 is regarded as the lower threshold of for successful detection in the area. The average scene coherence and its variation in the time series are presented in Fig. 4. There were two noteworthy periods where coherence was low during the study. The first drop in coherence in the $2015 / 08 / 15$ to $2015 / 09 / 06$ interferogram resulted in uncertainty regarding the end date of detected deformation for the confirmed event discussed in Section III. This coherence reduction occurred during the middle of the dry season and was not related to increases in vegetation growth. Perpendicular and temporal baselines were also relatively low for the interferometric pair in question (provided in Table I).

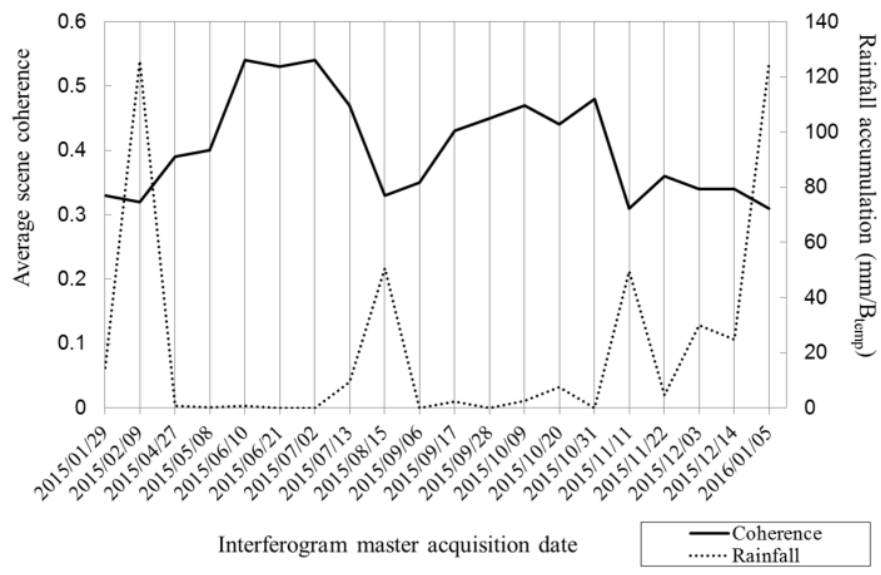

Fig. 4. Average global coherence and rainfall accumulation between the corresponding master and slave image acquisition dates. Two sudden drops in coherence are observed on master dates: 2015/08/15 and 2015/11/11.

However, as shown in Fig 4, rainfall accumulation between master and slave acquisitions was found to be associated with the sharp reduction in coherence. High intensity rainfall events or persistent rainfall over long periods may cause local disturbances to the surface, including a change in surface roughness, which may cause signal decorrelation explaining the observed coherence loss.

SAR incidence angle and line of sight (LOS) is a final consideration influencing the DInSAR performance. There is a real possibility of the subsidence signal being obscured by structures in the SAR's LOS if small-scale sinkholes occur in a complex urban environment [3]. Collecting data from descending and ascending satellite passes enables the observation of an area from the east and the west potentially mitigating LOS challenges. This also creates the opportunity to constrain the displacement vector further as there may be significant horizontal, as well as vertical, components to sinkhole precursors. 


\section{B. Geological Considerations}

The final and more fundamental limitations are due to the nature of sinkhole precursors themselves. It is possible that no precursory deformation precedes sinkhole development. The presence of chert bands in the study area, known for brittle failure without warning [21], affects the potential for precursory deformation to be expressed. Furthermore, competent land cover types, like concrete, buildings or paved roads may be resistant to deformation and mask the expression of precursory deformation at the surface. Moreover, precursory deformation might only occur shortly before the sinkhole and deformation signatures are therefore masked by the sinkhole event depending on the temporal frequency of image acquisitions. Finally, the deformation magnitude may be too large or small to be detectable, especially in the presence of signal noise. In all these cases, DInSAR would not be able to provide an early warning to sinkhole formation.

\section{Concluding Remarks}

This investigation illustrates the opportunities and challenges to detecting sinkhole precursors in South Africa's Gauteng Province using repeat-pass, X-band interferometry. It is expected that certain SAR and processing limitations can be addressed with advanced techniques and appropriate SAR data selection. It is recommended that future studies focus on processing workflows combining coherent targets (distributed and point) [19] together with conventional repeat-pass DInSAR. This approach would increase the probability of precursor detection by exploiting coherent targets while still enabling the detection of larger scale deformation features on areas without stable point targets assuming acceptable coherence conditions. Advanced filtering techniques can also be considered to improve interferogram quality [22].

Limitations related to the physical characteristics of sinkhole precursors remain fundamental to an early warning system based on ground deformation. Complementary groundbased methods are therefore expected to remain important for monitoring sinkhole-prone land [9].

The results of the investigation present evidence that deformation associated with sinkhole development can be detected by interferometry. There is, however, a need for more evidence of sinkhole precursor detections using various processing approaches and under different conditions globally. The resulting information will assist with the understanding of sinkhole dynamics as well as the operational limitations of DInSAR techniques in the context of a sinkhole early warning system.

\section{ACKNOWLEDGMENT}

The authors are grateful for ancillary data provided by the Council for Geoscience, the South African Weather Service and the Centre for Geographical Analysis at the Stellenbosch University. They also thank the reviewers for their critical analysis and valuable comments.

\section{REFERENCES}

[1] J. De Waele, F. Gutiérrez, M. Parise, and L. Plan, "Geomorphology and natural hazards in karst areas: A review," Geomorphology, vol. 134, no. 1-2, pp. 1-8, Nov. 2011.

[2] L. Chang and R. F. Hanssen, "Detection of cavity migration and sinkhole risk using radar interferometric time series," Remote Sens. Environ, vol.147, pp. 56-64, May 2014.

[3] E. Intrieri, G. Gigli, M. Nocentini, L. Lombardi, F. Mugnai, F. Fidolini, and N. Casagli, "Sinkhole monitoring and early warning: An experimental and successful GB-InSAR application," Geomorphology, vol. 241, pp. 304-314, Jul. 2015.

[4] C. E. Jones and R. G. Blom, "Bayou Corne, Louisiana, sinkhole: Precursory deformation measured by radar interferometry," Geology, vol. 42, no. 2, pp. 111-114, Dec. 2013.

[5] R. N. Nof, G. Baer, A. Ziv, E. Raz, S. Atzori, and S. Salvi, "Sinkhole precursors along the Dead Sea, Israel, revealed by SAR interferometry," Geology, vol. 4, no. 9, pp. 1019-1022, Jul 2013.

[6] M. L. Rucker, B. B. Panda, R. A. Meyers, and J. C. Lommler, "Using InSAR to detect subsidence at brine wells, sinkhole sites, and mines," Carbonates Evaporites, vol. 28 no. 1, pp. 141-147, May 2013.

[7] Z. Stevanovic, M. Parise, D. Closson, F. Gutiérrez, and Z. Stevanović, "Anticipating and managing engineering problems in the complex karst environment," Environ. Earth Sci., vol. 74, pp. 7823-7835, Jun. 2015.

[8] J. P. Galve, C. Castanada, F. Gutirezz, and G. Herrera, "Assessing sinkhole activity in the Ebro Valley mantled evaporite karst using advanced DInSAR," Geomorphology, vol. 229, pp. 30-44, Jan 2015.

[9] A. Ozden, A. Faghri, M. Li, and K. Tabrizi, "Evaluation of Synthetic Aperture Radar satellite remote sensing for pavement and infrastructure monitoring," Procedia Eng., vol. 145, pp. 752-759, 2016.

[10] K. E. Joyce, S. Samsonov, S. R. Levick, J. Engelbrecht, and S. Belliss, "Mapping and monitoring geological hazards using optical, LiDAR, and synthetic aperture RADAR image data," Nat. Hazards, vol. 73, no. 2, 137-163, Sept. 2014.

[11] K. Terwel and R. F. Hanssen, "Predicting structural disasters with Radar interferometry," in Proc. IABSE Symp., Sept. 2015, pp. 1-8.

[12] S. Richardson, "Sinkhole and subsidence record in the chuniespoort group dolomite, Gauteng, South Africa," M.S thesis, Dept. of Geology University of Pretoria, South Africa, 2013.

[13] A. Van Niekerk, "Stellenbosch University Digital Elevation Model (SUDEM)," Product description (2013 edition), pp. 1-13, 2014.

[14] R. M. Goldstein and C. L. Werner, "Radar interferogram filtering for geophysical applications," Geophys. Res. Lett., vol. 25, no. 21, pp. 4035-4038, Nov. 1998

[15] M. Costantini, "A novel phase unwrapping method based on network programming," IEEE Trans. Geosci. Remote Sens., vol. 36, no. 3, pp. 813-821, May 1998.

[16] A. Theron, "Detection of sinkhole precursors through SAR interferometry," M.S.c thesis, Dept. of Geography and Environmental Studies, Stellenbosch University, South Africa, 2017.

[17] A. Theron, J. Engelbrecht, J. Kemp, W. Kleynhans, and T. Turnbull, "Detection of sinkhole precursors through SAR interferometry: first results from South Africa," in Proc. IEEE Int. Geosci. Remote Sens. Symp., (IGARSS), Jul. 2016, pp. 5398-5401.

[18] D. Massonnet and K. L. Feigl, "Radar interferometry and its application to changes in the Earth's surface," Rev. Geophys., vol. 36, no. 4, pp. 441-500, Nov. 1998.

[19] A. Ferretti, A. Fumagalli, F. Novali, C. Prati, F. Rocca, and A. Rucci, "A new algorithm for processing interferometric data-stacks: SqueeSAR," IEEE Trans. Geosci. Remote Sens., vol. 49, no. 9, pp. 3460-3470, Sept. 2011

[20] J. Engelbrecht, C. Musekiwa, J. Kemp, and M. R. Inggs, "Parameters affecting interferometric coherence-the case of a dynamic agricultural region," IEEE Trans. Geosci. Remote Sens., vol. 52, no. 3, pp. 15721582. Mar. 2014

[21] D. J. Avutia, "Analytical and numerical study of dolomite sinkholes in Centurion, South Africa," M.S. thesis, Dept. of Civil Engineering, University of Cape Town, South Africa, 2014.

[22] G. Fornaro, S. Verde, D. Reale, and A. Pauciullo, "CAESAR: an approach based on covariance matrix decomposition to improve multibaseline-multitemporal interferometric SAR processing;" IEEE Trans. Geosci. Remote Sens., vol. 53, no. 4, pp. 2050-2065, Apr. 2015. 